\title{
Amphiphilic niobium oxyhydroxide as a hybrid catalyst for sulfur removal from fuel in a biphasic system
}

\author{
Luiz C.A. de Oliveira ${ }^{\mathrm{a}, *}$, Nathália T. Costa ${ }^{\mathrm{a}}$, Josefredo R. Pliego Jr ${ }^{\mathrm{b}}$, Adilson C. Silva ${ }^{\mathrm{a}}$, \\ Patterson P. de Souza ${ }^{c}$, Patrícia S. de O. Patrício ${ }^{c}$ \\ a Department of Chemistry, Universidade Federal de Minas Gerais, Av. Antônio Carlos 6627, Campus Pampulha, 31270-901, Belo Horizonte, MG, Brazil \\ b Department of Natural Sciences, Universidade Federal de São João del-Rey, 36301-160, São Joao del-Rei, MG, Brazil \\ ' Department of Chemistry, Centro Federal de Educação Tecnológica de Minas Gerais, CEFET-MG, Av. Amazonas 5253, 30421-169, Belo Horizonte, MG, Brazil
}

\section{A R T I C L E I N F O}

\section{Article history:}

Received 5 February 2013

Received in revised form 26 July 2013

Accepted 6 August 2013

Available online 18 August 2013

\section{Keywords:}

Modified niobia

Biphasic reaction

Heterogeneous catalysis

Oxidation process

\begin{abstract}
A B S T R A C T
Here, we show that a new niobium oxyhydroxide, $\mathrm{NbO}_{2} \mathrm{OH}$, can be synthesized and modified with a surfactant to be used as a heterogeneous catalyst for oxidative desulphurization. The material was treated with hydrogen peroxide to generate oxidizing groups (peroxo species) on the surface. Furthermore, this material was converted to a family of solid catalysts that can stabilize water/oil emulsions and catalyze reactions at the liquid/liquid interface by anchoring a surfactant to the catalyst. The material was then able to efficiently remove a sulfurous compound under mild conditions.
\end{abstract}

(C) 2013 Elsevier B.V. All rights reserved.

\section{Introduction}

Desulphurization of fuel oils has become an environmentally urgent subject worldwide. Environmental regulations have limited the sulfur levels in diesel fuels to less than 15 ppm since 2006 in the United States [1]. However, it is very difficult with current technology to decrease the sulfur content from several hundred $\mathrm{mg} / \mathrm{L}$ to only a few $\mathrm{mg} / \mathrm{L}[2,3]$. In the conventional hydrodesulphurization process (HDS), the use of high temperatures and pressures, large amounts of very active catalysts, long residence times, and large volume reactors are needed to effectively reduce the sulfur content to these low levels. Selective catalytic oxidation combined with extraction is one of the most promising desulphurization methods. Liquid/liquid extraction has been effectively utilized to remove sulfur and/or nitrogen molecules from petroleum distillates and synfuels [4]. However, this process is relatively inefficient due to the similar chemical characteristics of both sulfurous and nonsulfurous compounds. The more polar sulphones can be better extracted by polar solvents than sulphides; therefore, the efficiency of desulphurization via extraction can be significantly increased by oxidizing sulphides to sulphones [5,6]. Many oxidative systems

\footnotetext{
* Corresponding author. Tel.: +55 313409 7550; fax: +55 3134095700

E-mail address: luizoliveira@qui.ufmg.br (L.C.A. de Oliveira).
}

have been created, however, these systems have not been selective enough to oxidize only sulphides present in the fuel mixture. Furthermore, a large quantity of oxidant is required, increasing operating costs [7]. The amphiphilic catalyst (Nb-amp) reported in this work can selectively oxidize dibenzothiophene to the corresponding sulphone with stoichiometric amounts of $\mathrm{H}_{2} \mathrm{O}_{2}$ under mild conditions. Furthermore, the sulphone is removed in situ from hexane by acetonitrile during the reaction, and the catalyst can be recycled.

The solid structure that was obtained in this work permitted the generation of highly oxidizing surface groups by $\mathrm{H}_{2} \mathrm{O}_{2}$ treatment (Nb-hyd). These groups, peroxo-species, which have only been reported before in homogenous systems, can act as an effective oxygen donor in oxidation reactions [8-10]. However, some important reactions need more than an active catalyst. As reported in Science recently by Cole-Hamilton [11] and Crossley et al. [12], a catalyst that can simultaneously stabilize emulsions during the reaction would be highly advantageous in streamlining processes such as biomass refining. Both of these works and others [13] have used noble metals as the active catalyst. Here, we report a new family of solid catalysts based on the more common metal niobium that can stabilize water-oil emulsions by incorporating a hydrophobic surfactant on the catalyst and can catalyze reactions at the liquid/liquid interface in oxidative desulphurization processes. 


\section{Experimental}

\subsection{Synthesis and characterization}

The catalyst was prepared by first treating $0.26 \mathrm{M}$ $\mathrm{NH}_{4}\left[\mathrm{NbO}\left(\mathrm{C}_{2} \mathrm{O}_{4}\right)_{2}\left(\mathrm{H}_{2} \mathrm{O}\right)\right] \cdot\left(\mathrm{H}_{2} \mathrm{O}\right)_{n}$ with $1 \mathrm{M} \quad \mathrm{NH}_{4} \mathrm{OH} \quad(14.0 \mathrm{~mL})$, followed by heating at $70^{\circ} \mathrm{C}$ for $72 \mathrm{~h}$. This material was used as a precursor for the preparation of hydrophilic $\mathrm{NbO}_{2} \mathrm{OH}$ (Nb-hyd), obtained by treating pure niobia $(300 \mathrm{mg}$ ) with $30 \%$ aqueous $\mathrm{H}_{2} \mathrm{O}_{2}(4 \mathrm{~mL})$ in $\mathrm{H}_{2} \mathrm{O}(80 \mathrm{~mL})$ for $30 \mathrm{~min}$. The yellow solid was then filtered, washed with distilled water, and dried at $60^{\circ} \mathrm{C}$ for $12 \mathrm{~h}$. Then, the surfactant compound cetyltrimethylammonium bromide (CTAB, $4.47 \mathrm{mmol}$, Vetec) was added to a suspension of $\mathrm{NbO}_{2} \mathrm{OH}$ (Nb-hyd) in $\mathrm{H}_{2} \mathrm{O}$, and the mixture was refluxed for $4 \mathrm{~h}$ to prepare the amphiphilic hybrid material (Nb-amp). The resulting catalyst (yellow powder) was filtered, washed with water and dried at $60^{\circ} \mathrm{C}$. The materials were characterized by transmission electron microscopy (TEM) with a JEOL transmission electron microscope (model JEM 2000EXII).

A DIGIDROP-DI goniometer (GBX Instruments) was used to perform contact angle measurements. This system is equipped with a CCD camera and an automated liquid dispenser. The contact angle was determined by placing $\mathrm{H}_{2} \mathrm{O}$ droplets $(10 \mu \mathrm{L})$ on the surface of the samples using a syringe. The pure specimens were pressed to obtain disks. An image was taken and then analyzed to give an average angle between the droplet and the surface. Three consecutive measurements were made at room temperature using the Surface Energy mode of the software, which allows direct measurement of contact angle (in degrees).

Fourier transform infrared spectroscopy (FTIR) measurements of the catalyst were carried out with a Shimadzu Prestige 21 spectrophotometer equipped with an attenuated total reflectance (ATR) accessory. The spectra of the samples were obtained in the region from 4000 to $240 \mathrm{~cm}^{-1}$ using a CsI crystal with a resolution of $1 \mathrm{~cm}^{-1}$ and 100 signal-averaged scans.

Thermogravimetric analysis (TG/DTG) was performed using a DTG60 SHIMADZU. The samples were heated from room temperature to $800^{\circ} \mathrm{C}$ using a heating ramp of $100^{\circ} \mathrm{C} \mathrm{min}^{-1}$ under air flow $\left(150 \mathrm{~mL} \mathrm{~min}^{-1}\right)$.

\subsection{Catalytic tests}

The extraction-oxidation desulphurization experiments were conducted in a $20 \mathrm{~mL}$ round-bottom flask. For the catalytic studies $500 \mathrm{~mL}$ of a solution containing $1000 \mathrm{mg} / \mathrm{L}$ of dibenzothiophene dissolved in n-hexane (model compound of a fuel) was prepared. Of this solution, $10 \mathrm{~mL}$ was used to prepare the mixture with acetonitrile (extraction liquid) and the catalyst. The mixture, $1 \mathrm{~mL} \mathrm{H}_{2} \mathrm{O}_{2}$ $(30 \%, v / v)$ and $2 \mathrm{~mL}$ of acetonitrile was stirred vigorously at $25^{\circ} \mathrm{C}$ in the presence of $10 \mathrm{mg}$ of catalyst. After the reaction, the resulting mixture was placed in a static state to form two layers. The upper apolar phase (hexane) was separated easily from the nonpolar phase (acetonitrile) by decantation and its sulfur content analyzed by gas chromatography. Reuse of the catalyst tests: After $300 \mathrm{~min}$ of reaction, the catalyst was recovered by filtration of the modified mixture, followed by washing 3 times to remove the solvents. The material was then dried in an oven for $12 \mathrm{~h}$ at $70^{\circ} \mathrm{C}$.

The reaction products were analyzed by GC-MS (Agilent). The percentage of dibenzothiophene conversion was quantified by integrating the dibenzothiophene peak to the total ion content obtained before and after the reaction with the catalyst. GC-MS analysis was carried out with an injector temperature of $250^{\circ} \mathrm{C}$, an injection volume of $0.2 \mathrm{~mL}$, and a flow rate of $1.4 \mathrm{~mL} \mathrm{~min}^{-1}$ with an HP-5 column ( $5 \%$ polymethylphenylsiloxane). Each run used a heating curve of $110^{\circ} \mathrm{C}$ for $5 \mathrm{~min}$ then increasing by $3^{\circ} \mathrm{C} \mathrm{min}-1$ to $250^{\circ} \mathrm{C}$. The concentration in percentage of remaining DBT was monitored using a calibration curve (5 points) constructed with various concentrations of this compound. The calibration curve was performed in the two solvents, acetonitrile and hexane with a good linearity $\left(R^{2}>0.99\right)$.

\section{Results and discussion}

\subsection{Synthesis and characterization}

Fig. 1(A) shows images of $\mathrm{H}_{2} \mathrm{O}$ droplets on the $\mathrm{Nb}$-amp and $\mathrm{Nb}$ hyd surfaces. The Nb-hyd surface was completely wetted by $\mathrm{H}_{2} \mathrm{O}$, and the contact angle was measured as approximately $0^{\circ}$. However, the contact angle measured for Nb-amp was $76^{\circ}$, showing that the surfactant-containing catalyst had a significantly different surface composition compared to the catalyst without the surfactant. These results emphasized that the addition of a surfactant increased the hydrophobic character of the catalyst, suggesting that the surface groups are less available to make interactions with the droplet. This can, in turn, stabilize emulsions at the liquid-liquid interface, as confirmed by optical microscopy (Fig. 1(B)). This indicates that the size and type of quaternary ammonium cations play a vital role in the formation of a metastable emulsion droplet. We found that these metastable droplets are readily formed when the modified $\mathrm{NbO}_{2} \mathrm{OH}$ is stirred with acetonitrile and hexane. These emulsion droplets can be easily separated by centrifugation, and the catalyst can then be recycled. Furthermore, it is seen that Nbamp preferentially migrates to the biphasic interface of this solvent system (Fig. 1(D)), while Nb-hyd shows no such propensity. The material without the presence of surfactant is not stable at the polar/nonpolar interface of the solvents.

To observe possible morphological changes in the material due to the use of the surfactant, the samples were analyzed by transmission electron microscopy, with images shown in Fig. 1(C) and (D). As shown in Fig. 1(C), the material (Nb-hyd) presents the regular morphology of agglomerated particles. Fig. 1(D) (Nb-amp) shows poor image contrast, which is typical of nanoparticles dispersed in the presence of surfactant. This effect of a surfactant on the surface of catalysts has been described in the literature [14].

The presence of the surfactant molecule over the catalyst was identified by infrared spectroscopy (Fig. 2). The more intense bands in the CTAB spectrum are located in the region between 3050 and $2700 \mathrm{~cm}^{-1}$. The bands at approximately 2916 and $2848 \mathrm{~cm}^{-1}$ are associated to the symmetric $\left(\nu_{\mathrm{s}}\right)$ and asymmetric $\left(\nu_{\mathrm{a}}\right)$ stretching modes of $\mathrm{CH}_{2}$, respectively. These bands appear in the spectrum of $\mathrm{Nb}$-amp sample, indicating the presence of the surfactant in the catalyst structure. To identify the possible bonding between the surfactant and the catalyst, specific regions of the $\mathrm{Nb}$-hyd and $\mathrm{Nb}$ amp FTIR spectra were evaluated. The two main spectral regions of interest are at $3600-3000 \mathrm{~cm}^{-1}$ and $950-500 \mathrm{~cm}^{-1}$. The first is the sum contribution of different hydroxyl group absorptions at the hybrid catalyst surface. The bands at about $3412 \mathrm{~cm}^{-1}$ and $3140 \mathrm{~cm}^{-1}$ are assigned to the $\mathrm{O}-\mathrm{H}$ stretching vibration localized at the surface and in the bulk structure, respectively [16]. The extent of $\mathrm{O}-\mathrm{H}$ bulk or surface groups can be evaluated based on the ratio between the area below each hydroxyl band and total area of the bands $\left(A_{\mathrm{O}-\text { Hsurface }}+A_{\mathrm{O}-\mathrm{Hbulk}}\right)$. A fraction of $\mathrm{O}-\mathrm{H}$ bulk groups $\left(A_{\mathrm{O}-\mathrm{Hbulk}} / A_{\text {total }}=0.67\right)$ is significantly larger than the $\mathrm{O}-\mathrm{H}$ surface groups $\left(A_{\mathrm{O}-\text { Hsurface }} / A_{\text {total }}=0.32\right)$ to $\mathrm{Nb}$-hyd. The ratio between these fractions is approximately 2 . After the addition of surfactant to the catalyst, the inversion of relative intensity of these bands followed, for Nb-amp the high frequency band at $3186 \mathrm{~cm}^{-1}$, became more intense. Moreover, two new bands centred at $3541 \mathrm{~cm}^{-1}$ and $3323 \mathrm{~cm}^{-1}$ besides those present were revealed by the deconvolution of the $\mathrm{O}-\mathrm{H}$ stretching region related to $\mathrm{Nb}-\mathrm{amp}$ (Fig. 2). These bands in high frequencies, when compared to the 
A
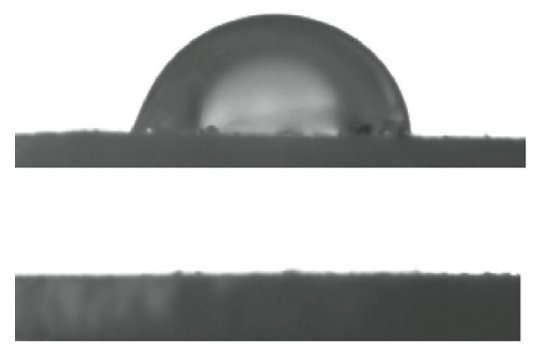

C

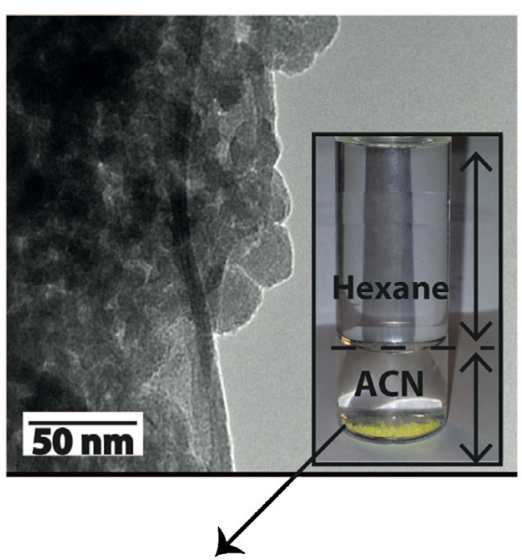

Catalyst (Nb-hyd)

in the polar solvent
B

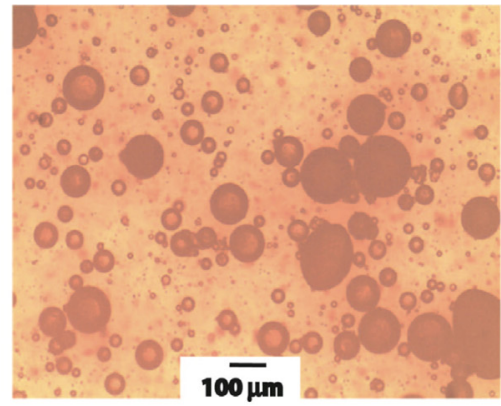

D

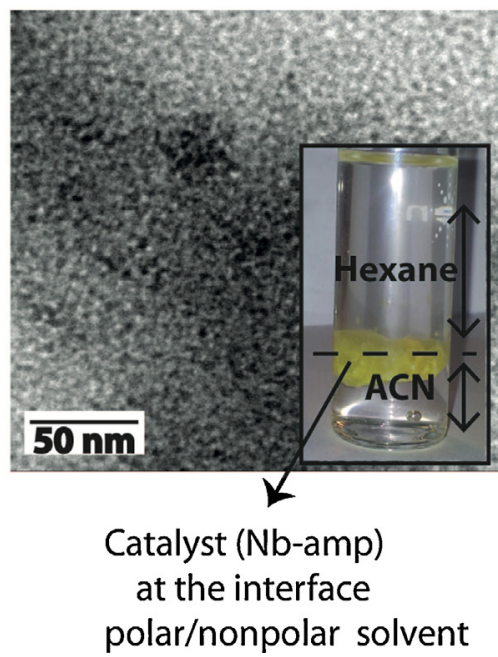

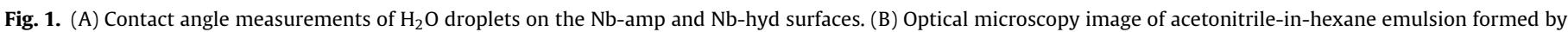

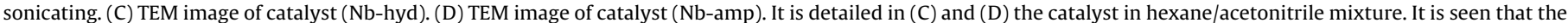
amphiphilic catalyst preferentially migrates to the interface.

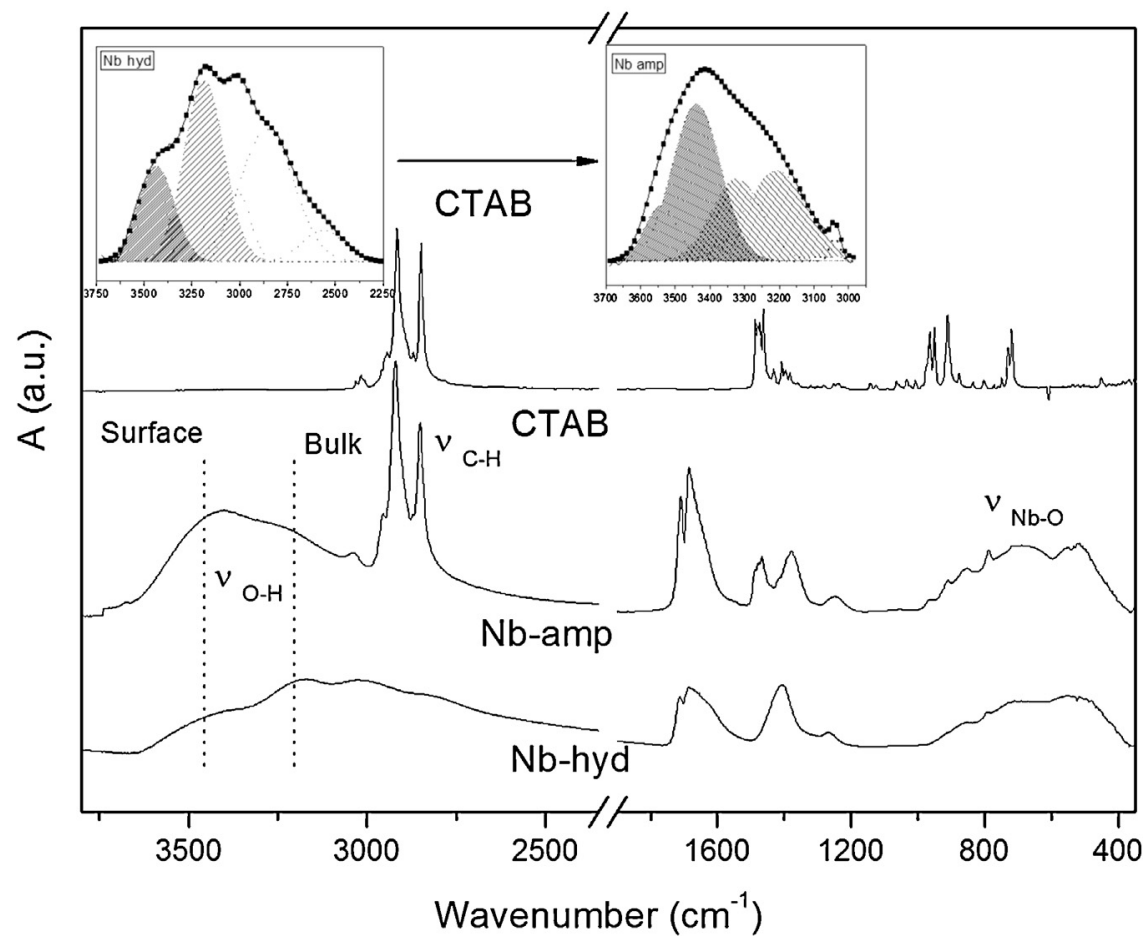

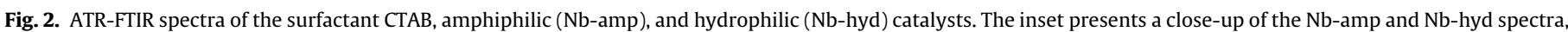
showing deconvoluted FTIR spectrum of samples: carbonyl stretching region. 


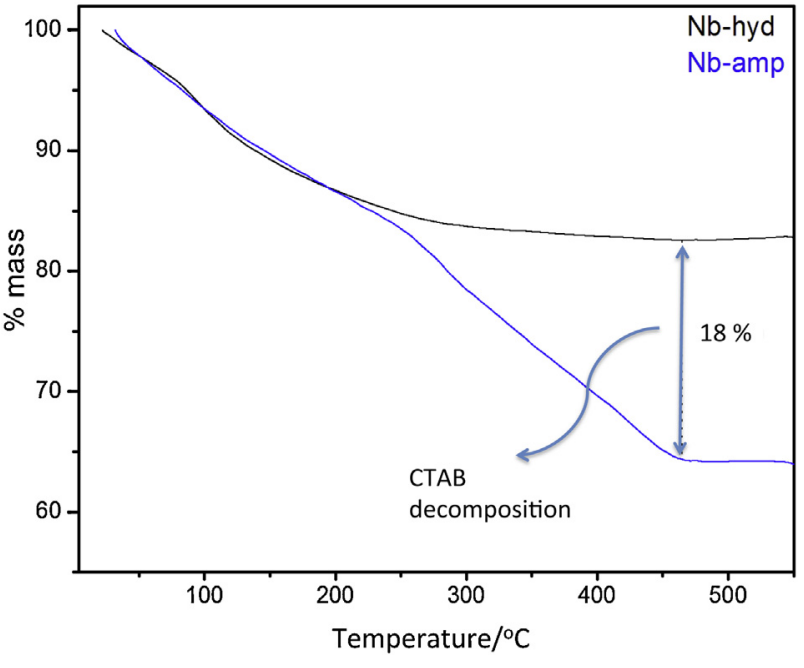

Fig. 3. TGA analyses of the catalysts Nb-hyd and Nb-amp.

$\mathrm{Nb}$-hyd, were associated with new linkage involved in the $\mathrm{O}-\mathrm{H}$ surface (at $3541 \mathrm{~cm}^{-1}$ ) and bulk (at $3323 \mathrm{~cm}^{-1}$ ) groups of niobium oxyhydroxide and surfactant. The deconvolution mathematical procedure overcame an overlapping in absorption of the hydroxyl band from bulk and surface linkage and no link with the surfactant. The following ratio of areas, $A_{\mathrm{O}-\mathrm{H} \text { surfacelinkageCTAB }} / A_{\mathrm{O}-\mathrm{H} \text { surface }}$ and $A_{\mathrm{O}-\text { Hbulk-linkageCTAB }} / A_{\mathrm{O}-\text { Hbulk }}$ was used to investigate the extent of $\mathrm{O}-\mathrm{H}$ group linkage to the surfactant. The ratio increase of $0.24-0.75$ indicated that the CTAB linkage is involved preferentially to the $\mathrm{O}-\mathrm{H}$ group bulk. Furthermore, the ratio of the fractions of $\mathrm{O}-\mathrm{H}$ bulk $\left(A_{\mathrm{O}-\text { Hbulk-linkageCTAB }}+A_{\mathrm{O}-\text { Hbulk }}\right) /\left(A_{\mathrm{O}-\text { HsurfacelinkageCTAB }}+A_{\mathrm{O}-\text { Hsurface }}\right)$ and $\mathrm{O}-\mathrm{H}$ surface decreased by approximately 1 , when compared to the value of Nb-hyd. This result can be explained due to the substitution of the $\mathrm{O}-\mathrm{H}$ groups of the bulk by the surfactant that promotes strong interactions between the hydroxyl of the niobium oxyhydroxide and the surfactant groups.

In addition, the possibility of interactions between CTAB and the $\mathrm{Nb}=\mathrm{O}, \mathrm{Nb}-\mathrm{O}$ or $\mathrm{Nb}(\mathrm{O}-\mathrm{O})$ groups to a lesser extent can explain the slight changes observed in the second region of the two spectra. The bands that appear between 950 and $500 \mathrm{~cm}^{-1}$ are assigned to the $\mathrm{Nb}-\mathrm{O}$ and $\mathrm{O}-\mathrm{O}$ stretching vibrations [15,17-19]. The Nb-amp spectrum shows a larger number of shoulders in this region, indicating that the new interactions between the surfactant and catalyst interfere with the vibrational modes of these catalyst groups.

The thermogravimetric analysis is shown in Fig. 3. Both materials with and without surfactant incorporated, have a very similar weight loss profile up to about $250^{\circ} \mathrm{C}$. That mass change must be due to the loss of water and also hydroxyl groups. However, above this temperature the material containing hydrophobic groups (Nbamp) loses $18 \%$ of mass, while the catalyst Nb-hyd has no mass loss. Thus, we believe that the catalyst Nb-amp has a content of $18 \%$ by weight of surfactants groups on its surface.

\subsection{Theoretical studies}

\subsubsection{Ab initio study of the $\mathrm{NbO}_{2} \mathrm{OH}$ structure}

To understand the structure of this niobium oxyhydroxide material and how its surface interacts with the surfactant, we have performed some theoretical calculations using a cluster model. Based on the $\mathrm{NbO}_{2} \mathrm{OH}$ stoichiometry, it was considered to exist as a cluster of $18 \mathrm{Nb}$ atoms with terminal oxygen atoms each attached to a hydrogen atom. In addition, we considered the surface to be covered by hydroxyl groups. The model has the formula $\mathrm{Nb}_{18} \mathrm{O}_{75} \mathrm{H}_{62}$. Because it is a large system, geometry optimization was conducted at the Hartree-Fock level with the SBKJC Effective

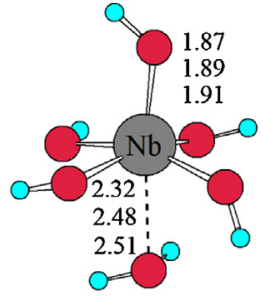

HF/SBKJC $\mathrm{HF} / \mathrm{SBKJC}+\mathrm{P}(\mathrm{d})$ $\mathrm{X} 3 \mathrm{LYP} / \mathrm{SBKJC}+\mathrm{P}(\mathrm{d})$

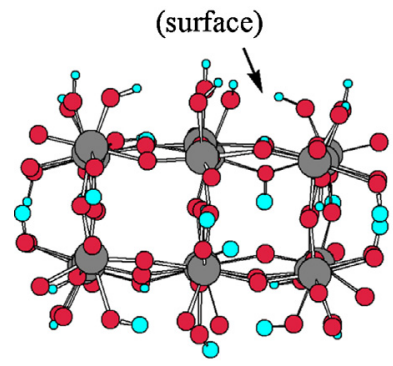

(Top view of the surface)

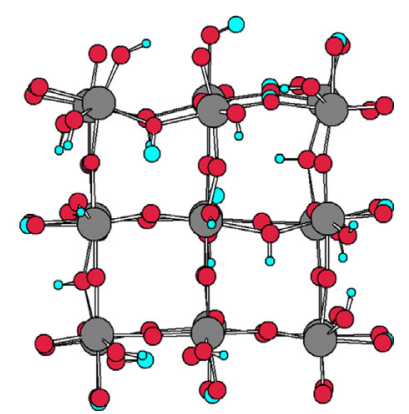

Fig. 4. Structure of the $\mathrm{Nb}(\mathrm{OH})_{5} \mathrm{H}_{2} \mathrm{O}$ model species at different levels of theory and the $\mathrm{Nb}_{18} \mathrm{O}_{75} \mathrm{H}_{62}$ cluster (without terminal hydrogen atoms at non-surface edges) obtained at the HF/SBKJC level. Only singlet states were considered.

Core Potential (ECP) and the respective SBKJC basis set. However, we have tested the reliability of this level of theory by optimizing the structure of $\mathrm{Nb}(\mathrm{OH})_{5} \mathrm{H}_{2} \mathrm{O}$ model at the $\mathrm{HF}$ level with the SBKJC basis set and also by adding $\mathrm{d}$ polarization functions on the $\mathrm{Nb}$ and $\mathrm{O}$ atoms $(\mathrm{SBKJC}+\mathrm{P}(\mathrm{d})$ basis set). Density functional theory calculations with the X3LYP functional and the SBKJC+P(d) basis set were also performed (Fig. 4). From the calculations, we noticed a distorted octahedral structure around the $\mathrm{Nb}$ atoms. The $\mathrm{Nb}-\mathrm{OH}$ distance was slightly changed by the level of theory, while the difference in bond length was larger for $\mathrm{Nb}-\mathrm{OH}_{2}$.

Considering the long computational time required for the optimization of this large $\mathrm{Nb}_{18} \mathrm{O}_{75} \mathrm{H}_{62}$ cluster, we believe that the $\mathrm{HF} / \mathrm{SBKJC}$ calculations are a reasonable approach. The octahedral geometry around the $\mathrm{Nb}$ atom is even more distorted due to the hydrogen bonds between the hydrogen atoms of the hydroxyl groups and the vicinal oxygen atoms. The $\mathrm{Nb}-\mathrm{O}$ distances are in the range of $1.8-2.2 \AA$, whereas many hydrogen bonds are approximately $1.8 \AA$.

\subsubsection{Structure of the modified $\mathrm{NbO}_{2} \mathrm{OH}$ surface}

The present experimental data indicate that the surfactant is bound to the $\mathrm{NbO}_{2} \mathrm{OH}$ surface according to infrared spectrum. Thus, we need a model able to explain the structure of the catalyst. Considering that the normal $\mathrm{NbO}_{2} \mathrm{OH}$ surface is fully covered by $\mathrm{OH}$ groups, the formation of the peroxo group and adsorption of the surfactant on the surface can be viewed as the process presented in Fig. 5. The quaternary ammonium ion is bound by an electrostatic interaction and we can notice the peroxo groups become interaction sites. To verify the stability of this structure, we have performed ab initio calculations using a smaller cluster, $\mathrm{Nb}_{8} \mathrm{O}_{37} \mathrm{H}_{31}$, interacting with the $\mathrm{N}\left(\mathrm{CH}_{3}\right)_{4}{ }^{+}$ion. Geometry optimization was performed at the HF/SBKJC level of theory, and the obtained structure is presented in Fig. 5. It can be observed that the structure proposed is stable, and the surfactant stays close to both the oxo and the peroxo groups. The structure of the surface peroxo group suggests that the oxidation process is a single oxygen transfer from the surface to the substrate. The close proximity between the surfactant and the surface peroxo group allows the oxidation of low polarity substrates. In fact, the floppy nature of 

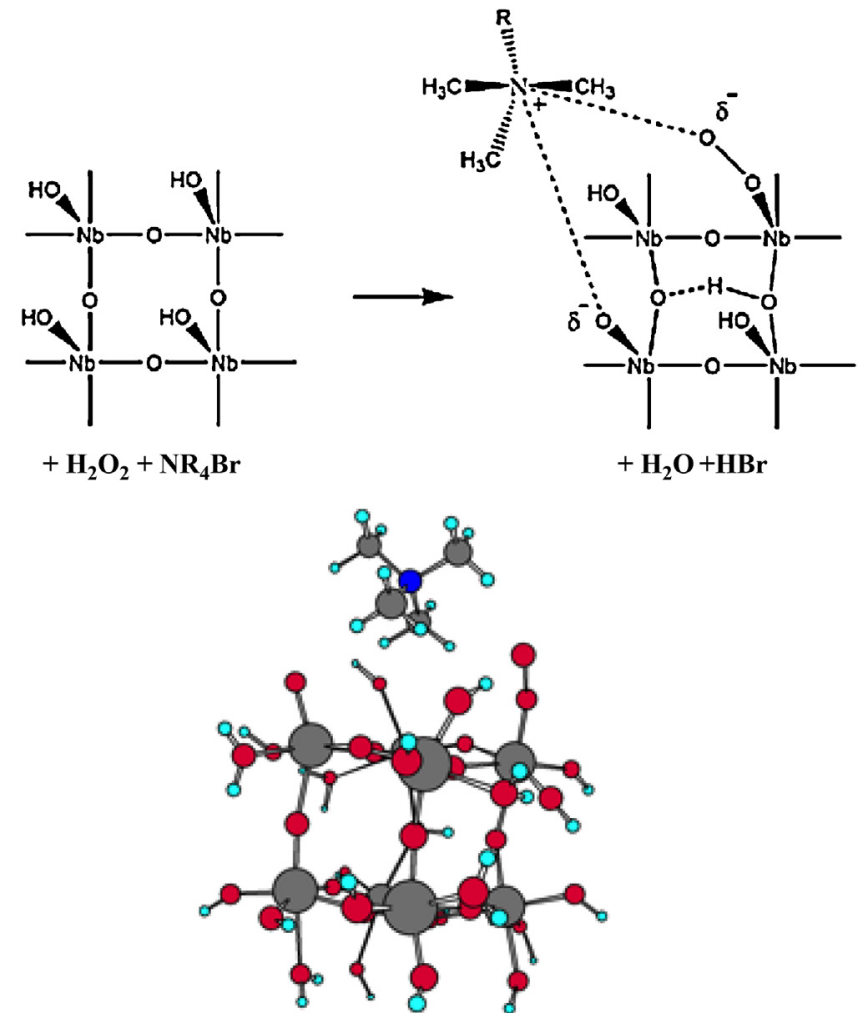

Fig. 5. Formal process for the amphiphilic $\mathrm{NbO}_{2} \mathrm{OH}$ surface formation and structure of the Nb-amp catalyst modelled as the interaction of the $\mathrm{Nb}_{8} \mathrm{O}_{36} \mathrm{H}_{32} \mathrm{Br}^{-}$cluster (without terminal hydrogen atoms at non-surface edges) with the $\mathrm{N}\left(\mathrm{CH}_{3}\right)^{4+}$ ion obtained at the HF/SBKJC level.

the minimum energy structure between the surfactant cation and the surface allows its easy mobility. As consequence, no steric repulsion should be observed between the surfactant cation and the sulphide reactant during the oxidation reaction. The present proposal is compatible with the experimentally observed reaction.

\subsection{Catalytic tests}

To illustrate the application of the hybrid catalyst in a liquid/liquid reaction system, we chose the selective oxidation of dibenzothiophene (DBT) as a model reaction. DBT was used as a model molecule because it is representative of the most stable sulfurous molecules in oil and constitutes the majority of the sulfurous molecules remaining in diesel after HDS treatment [8]. Fig. 6 shows the conversion of DBT over time at room temperature using the $\mathrm{Nb}$-amp catalyst.

These results demonstrate that DBT is almost completely oxidized into the corresponding sulphone by $90 \mathrm{~min}$ at $25^{\circ} \mathrm{C}$. Only stoichiometric $\mathrm{H}_{2} \mathrm{O}_{2}$ is consumed, and the turnover number (TON) is estimated to be higher than 218 . These results indicate that the $\mathrm{Nb}$-amp catalyst in the emulsion is very active and selective for the oxidation of DBT to the sulphone even at room temperature. The catalyst without surfactant incorporation (Nb-hyd) did not present a high oxidation capacity (ca. 19\% after $60 \mathrm{~min}$ ) because it remained in the polar phase, disallowing the reaction with DBT dissolved in the nonpolar phase. Since the peroxo groups replace the acid group on the surface [20] it is possible to obtain the peroxo group amount considering the decreasing in the acid sites after the $\mathrm{H}_{2} \mathrm{O}_{2}$ treatment (as described in Section 2) to obtain the $\mathrm{Nb}$-amp catalyst. The titration of $\mathrm{NaOH}(0.0097 \mathrm{~mol} / \mathrm{L})$ excess with $\mathrm{HCl}(0.0084 \mathrm{~mol} / \mathrm{L})$ showed that the acid sites amount was $7.11 \times 10^{19}$ and $5.47 \times 10^{19} \mathrm{H}^{+}$sites/g for $\mathrm{Nb}$-amp before and after

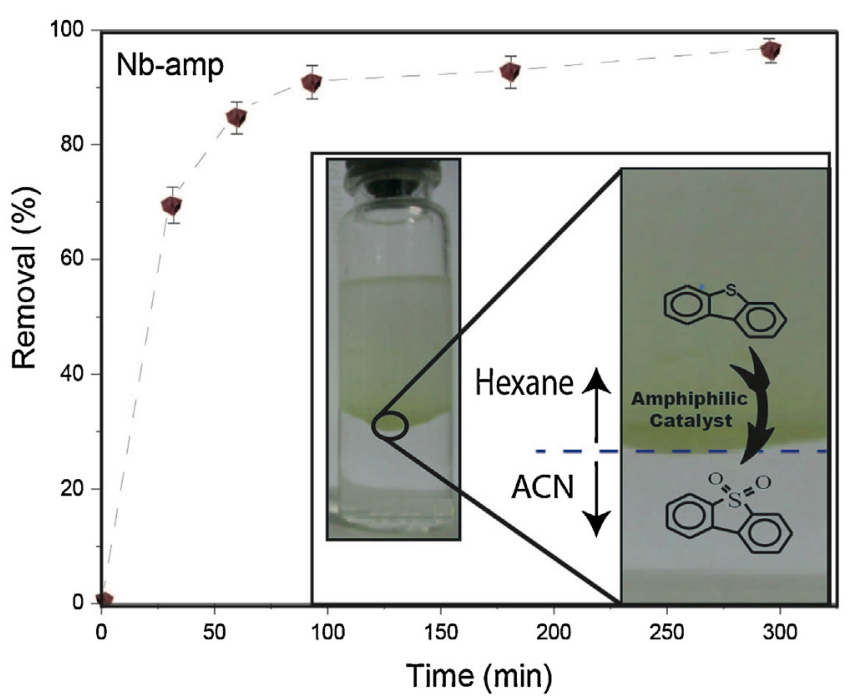

Fig. 6. Profile of DBT removal and details of amphiphilic niobium oxyhydroxide particles at the interface of biphasic system.

$\mathrm{H}_{2} \mathrm{O}_{2}$ treatment, respectively. The peroxo group amounts can be obtained by the difference between these values, i.e., $1.64 \times 10^{19}$ peroxo sites/g. Considering that $10 \mathrm{mg}$ of catalyst in the reactions was used, the number and peroxo sites are $1.64 \times 10^{17}$. Whereas the number of molecules converted after $300 \mathrm{~min}$ of reaction was $3.27 \times 10^{19}$, the value of TON is approximately 218 .

Fig. 7 shows the sulfur-specific gas chromatography (GC-MS) analyses of DBT in hexane before and after the catalytic oxidation at $60 \mathrm{~min}$. It is worthwhile to note all of the sulfurous molecules were almost completely oxidized into sulphones, which consequently were completely extracted in situ by the polar extractant. The used catalyst was easily separated from the reaction system by filtration. After four cycles, the catalyst showed almost the same catalytic performance as unused material, indicating that the catalyst can be recycled and reused for this reaction.

The advantage of operating in a biphasic system with the catalyst at the liquid/liquid interface is the possibility of conducting the process in a single step instead of two by skipping the separation. The oxidized molecules with higher polarity migrate to the polar phase after reaction with the peroxo species on the catalyst (Fig. 6 detail), facilitating their separation from the hydrocarbon molecules. It is important to note that surface modification of

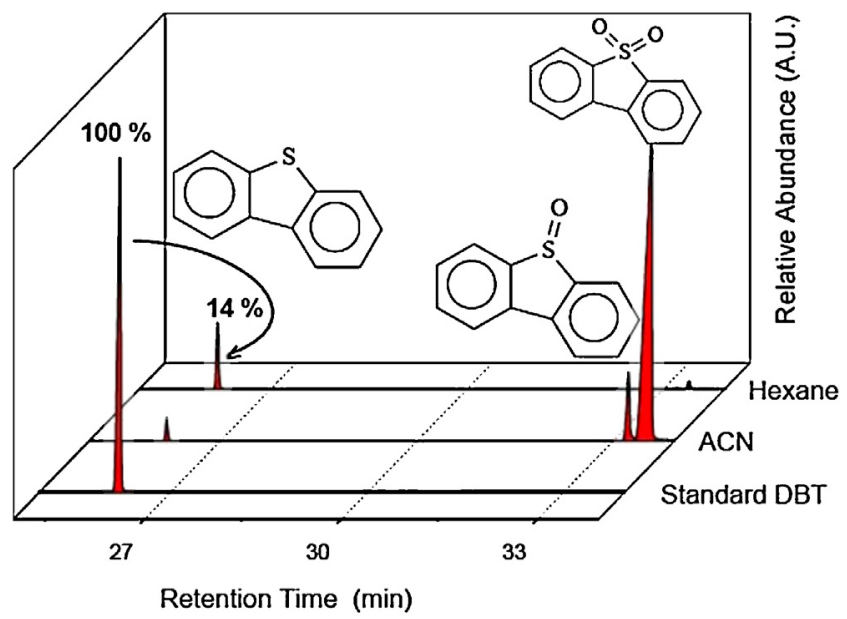

Fig. 7. Chromatograms of standard DBT in hexane before reaction, acetonitrile phase after reaction, and hexane phase after reaction. 
niobium has only been shown with the synthetic route presented in this work. This means that the formation of niobium oxyhydroxide instead of niobium oxide permits the generation of the peroxospecies (oxidizing agent) while also facilitating the anchoring of the surfactant molecule (hydrophobization of the catalyst). Our results highlight the applications of solid catalysts based on modified niobium compounds localized at the interface of two liquid phases. Finally, the results presented in this work open a new field of study using new compounds of niobium. These versatile compounds may be modified through generation of oxidizing groups as shown here or impregnated with other metals aiming towards their application in different types of catalytic reactions.

\section{Conclusion}

A new niobium oxyhydroxide has been modified and studied as a heterogeneous catalyst for oxidative desulphurization due to the production of oxidizing groups on the catalyst. Furthermore, this material was converted to a family of solid catalysts that can stabilize in water/oil emulsions and catalyze reactions at the liquid/liquid interface by anchoring a surfactant. The material was then able to efficiently remove a sulfurous compound under mild and biphasic conditions. Theoretical calculations and FTIR analyses showed that the peroxide group and surfactant species are anchoring, replacing $-\mathrm{OH}$ on the catalyst. Furthermore, unexpected data showed that the peroxide group is not a radical, as reported by some authors. This result suggests that the oxidation process is a single oxygen transference from the surface to the substrate with no radical involvement. Finally, the results presented in this work open a new field of study using new compounds of niobium. These versatile compounds may be modified through generation of oxidizing groups as shown here or impregnated with other metals aiming towards their application in different types of catalytic reactions.
In addition, the possibility of transformation into an amphiphilic material enables its wider use to be employed in various industrial processes.

\section{Acknowledgments}

This work was supported by the CNPq, FAPEMIG, CAPES and Pro-Reitoria de Pesquisa-UFMG.

\section{References}

[1] U. E.P.A., Heavy-duty engine and vehicle standards and highway diesel fuel sulfur control requirements, 2000, pp. 1.

[2] C. Li, Z. Jiang, J. Gao, Y. Yang, S. Wang, F. Tian, F. Sun, X. Sun, P. Ying, C. Han, Chem.-Eur. J. 10 (2004) 2277.

[3] J. Torres-Nieto, W.W. Brennessel, W.D. Jones, J.J. García, J. Am. Chem. Soc. 131 (2009) 4120 .

[4] P.S. Tam, J.R. Kittrell, J.W. Eldridge, Ind. Eng. Chem. Res. 29 (1990) 321.

[5] C.S. Castro, M.C. Guerreiro, L.C.A. Oliveira, M. Goncalves, A.S. Anastacio, M. Nazzarro, Appl. Catal. A: Gen. 367 (2009) 53.

[6] W. Ferraz, L.C.A. Oliveira, R. Dallago, L.D. Conceição, Catal. Commun. 8 (2007) 131.

[7] S. Murata, K. Murata, K. Kidena, M.A. Nomura, Energy Fuels 18 (2004) 116

[8] C. Bolm, F. Bienewald, Angew. Chem. Int. Ed. Engl. 34 (1996) 2640.

[9] D. Bayot, M. Devillers, Coord. Chem. Rev. 250 (2006) 2610.

[10] M. Anilkumar, W.F. Hoelderich, J. Catal. 293 (2012) 76.

[11] D.J. Cole-Hamilton, Science 327 (2009) 41.

[12] S. Crossley, J. Faria, M. Shen, D.E. Resasco, Science 327 (2009) 68.

[13] D.M. Andala, S.H.R. Shin, H.-Y. Lee, K.J.M. Bishop, ACS Nano 6 (2012) 1044

[14] R. Khurana, S. Vaidya, M.M. Devi, A.K. Ganguli, J. Colloid Interface Sci. 352 (2010) 470.

[15] Y. Jun, X.Y. Zhu, J. Am. Chem. Soc. 126 (2004) 13224.

[16] M. Ristić, S. Popović, S. Musić, Mater. Lett. 58 (2004) 2658.

[17] J.J. Boruah, D. Kalita, S.P. Das, S. Paul, N.S. Islam, Inorg. Chem. 50 (2011) 8046.

[18] A.P.L. Batista, H.W.P. Carvalho, G.H.P. Luz, P.F.Q. Martins, M. Goncalves, L.C.A Oliveira, Environ. Chem. Lett. 8 (2010) 63.

[19] A. Esteves, L.C.A. Oliveira, T.C. Ramalho, M. Goncalves, A.S. Anastacio, H.W.P. Carvalho, Catal. Commun. 10 (2008) 330.

[20] A.C. Silva, D.Q.L. Oliveira, L.C.A. Oliveira, A.S. Anastácio, T.C. Ramalho, J.H. Lopes, H.W.P. Carvalho, C.E.R. Torres, Appl. Catal. A: Gen. 357 (2009) 79. 